\title{
Una fundación de doña María de Silva y Toledo (1494- 1544): La obra tardogótica y los maestros del monasterio de clarisas de Medinaceli
}

\author{
A foundation of Dona Maria de Silva and Toledo (1494- \\ 1544): The late Gothic work and the master of the \\ monastery of Clarisse Nuns of Medinaceli
}

\author{
Raúl ROMERO MEDINA \\ Universidad Internacional de la Rioja
}

Recibido: 7-III-2016

Aceptado: 23-VI-2016

Resumen: María de Silva y Toledo, duquesa de Medinaceli, fundó un monasterio de monjas de Santa Clara en la villa de Medinaceli en 1528. Para su construcción la duquesa contó con conocidos maestros entre los que se encuentran Juan Vélez, Alonso de Covarrubias y Juan de Carasa, artistas importantes para comprender la evolución de las formas tardogóticas a las renacentistas en Castilla.El presente trabajo analiza la fundación del monasterio y valora el proceso de ejecución de la obra en el contexto arquitectónico del momento.

Palabras clave: María de Silva y Toledo, Monasterio de monjas de Santa Clara, Medinaceli, Juan Vélez, Alonso de Covarrubias, Juan de Carasa,Tardogótico, Renacimiento.

Aвstract: Maria de Silva and Toledo, Duchess of Medinaceli, founded a monastery of Clarisse nuns in the town of Medinaceli in 1528. For its construction, the duchess employed important masters like Juan Velez, Alonso de Covarrubias and Juan de Carasa, builders for understanding of the evolution from late Gothic to Renaissance forms in Castile. This paper analyzes the foundation of the monastery and evaluates the implementation process of the work in the architectural context of the moment.

Keywords: Maria de Silva y Toledo, Monastery of Clarisse nuns, Medinaceli, Juan Vélez, Alonso de Covarrubias, Juan de Carasa, Late Gothic, Renaissance.

La nobleza titulada jugó un papel importante en la actividad fundacional de conventos en la España Moderna ${ }^{1}$. Los estados

${ }^{1}$ El presente artículo se ha elaborado en el marco del Proyecto Construir y conservar lealtades colectivas. Sobera- señoriales, y las ciudades emblemáticas a ellos asociados, eran los perfectos escenarios

nía y élites en la Monarquía de España (siglos XVI-XVII), Ref. HAR2012-39016-C04-02, Ministerio de Ciencia e Innovación del Gobierno de España. 
en los que desarrollar políticas de prestigio, promoción y proyección social del linaje ${ }^{2}$. La arquitectura era una forma de expresar el poder y una garantía para mantener y reproducir la dignidad y el honor familiar, por lo que no importaba emplear grandes cantidades económicas para sufragar los gastos de las obras de estas fundaciones y contar con los mejores arquitectos del momento, si la intención era la exaltación de los vínculos de sangre y la perpetuación de la calidad social heredada, es decir, del linaje, en los territorios en los cuales se ejercía el poder.

En este sentido, Morant y Bolufer han afirmado que "el honor familiar se representaba en buena medida a través de la mujer"3 . Así, en línea con los recientes estudios de género, se viene analizando el papel que jugó la élite femenina en relación con los asuntos nobiliarios de las principales familias y linajes en la historia de la España altomoderna ${ }^{4}$. Por ello, se ha incidido con detalle en el análisis de las relaciones entre las mujeres y las fundaciones conventuales, y especialmente se ha tratado la implicación de las damas de la nobleza como promotoras de fundaciones y obras arquitectónicas ${ }^{5}$. A pesar de que en una sociedad como la del

${ }^{2}$ A. ATIENZA, Tiempos de conventos. Una historia social de las fundaciones en la España Moderna, Madrid, 2008.

${ }^{3}$ I. MORANT DEUSA y M. BOLUFER PERUGA, Amor, matrimonio y familia. La construcción histórica de la familia moderna, Madrid, 1998, p. 50.

${ }^{4}$ En este sentido, podemos destacar la reciente monografía que analiza el papel que las hijas, nietas y biznietas de don Íñigo López de Mendoza, Marqués de Santillana, tuvieron en sus estados territoriales en calidad de damas Mendoza. Cfr. E. ALEGRE CARVAJAL (dir.), Damas de la Casa Mendoza. Historias, leyendas y olvidos, Madrid, 2014.

5 Diferentes investigaciones han contribuido al avance del conocimiento en este campo. Por citar alguna aportación, cabe destacar el trabajo de J. HIDALGO OGÁYAR, "La familia Mendoza ejemplo de patronazgo femenino en la Edad Moderna", en G. LEVI y A. RODRÍGUEZ PÉREZ (eds.), Familia, movilización y jerarquización social, Murcia, 2010, pp. 297-310 y A. M. ARANDA BERNAL, "La participación de las mujeres en la promoción artística durante la Edad Moderna", Goya, Revista de Arte, vol. 301-302, 2005, pp. 229-240.
Antiguo Régimen, marcada fuertemente por la presencia masculina, no eran muchas las que gozaban de independencia económica y jurídica, la familia del rey y sus círculos más próximos, junto con monjas y viudas, eran las excepciones que confirmaban la regla de este colectivo ${ }^{6}$.

Así las cosas, era bastante frecuente que estas mujeres pusieran bajo su amparo o protección alguna fundación de carácter religioso y benéfico en los territorios vinculados a su familia, pues era una forma de gestionar la memoria. Su labor como patronas ha quedado demostrada no solo en la implicación arquitectónica, sino en el concepto más amplio de la palabra patronazgo que englobaría también la dotación de estos espacios con destacadas piezas artísticas de diversa índole. Ello ha permitido acuñar el término de matronazgo con idéntico valor y alcance a su equivalente de género ${ }^{7}$, es decir, patronazgo, concepto que se apoya en el sistema patriarcal y en la nobleza en la idea de descendencia por vía recta de varón. Queda mucho por hacer, pues carecemos de una visión de conjunto, y habría que analizar si existen diferencias o similitudes entre el mecenazgo arquitectónico ejercido por los hombres y el practicado por las mujeres, pues se ha señalado que el patronato era fundamentalmente una cuestión masculina.

El caso de la duquesa de Medinaceli, María de Silva y Toledo (1494-1544), encaja a la perfección con el grupo de miembros directamente conectados con la corte por su linaje, los Silva, condes de Cifuentes, y los de

\footnotetext{
${ }^{6}$ Estos trabajos parten sobre todo de la historiografía del ámbito americano donde se han hecho contribuciones como las de E. SHERY, REISS y D.G. WILKINS (eds.), Beyond Isabella. Secular women Patron of Art in Renaissance Italy, New Caledonia, 2001 o C. LAWRENCE (ed.), Women and Art in the Early Modern Europe. Patrons, Collectors and Connoisseurs. Pennsylvania, 1997.
}

${ }^{7}$ Sobre la práctica de las mujeres en la arquitectura y sobre el concepto de matronazgo reflexiona el trabajo de M. E. DIEZ JORGE, "Investigar sobre la arquitectura y el género: teoría y práctica de un proyecto", Revista Arenal, 21:1, 2014, pp. 179-190. 
la Cerda, duques de Medinaceli, y el papel que este estaba desempeñando en la corte de Carlos V. La unión de estos dos linajes dio un poder excepcional a la familia, pues los Silva se beneficiaron de las influencias de los Medinaceli en la corte, sobre todo del inmenso poder ejercido por el gran Cardenal Pedro González de Mendoza en tiempos de los monarcas católicos ${ }^{8}$. Favorecidos por esta unión, los Silva aumentaron su poder en territorios de Castilla.

El presente trabajo se centra en la actividad fundacional que la duquesa de Medinaceli, María de Silva y Toledo (1494-1544), llevó a cabo, apoyando a la corriente espiritual del franciscanismo femenino reformado al favorecer el establecimiento de una comunidad de monjas clarisas en la villa de Medinaceli y patrocinar su obra en unos momentos en los que la arquitectura castellana evolucionaba desde las formas del tardogótico al primer renacimiento.

Su labor como patrona, traducida en arquitectura, llevó implícita una red social y humana ciertamente vinculada con su linaje, pero también con su condición de mujer. En este sentido, la devoción franciscana de su familia paterna, los Silva, fue determinante para la fundación llevada a cabo en la villa de Medinaceli y la elección de algunos maestros que intervienen en la obra nos ofrece una visión muy particular entre género y nobleza, ya que su condición de mujer fue determinante en el contexto de la cultura visual del momento al conjugar identidad personal, religiosa y nobiliaria. Así, el análisis de la ejecución de la obra y su valoración en el contexto arquitectónico del momento, junto con la formulación de una hipótesis y argumentación sobre el autor de la traza, resulta determinante para reafirmar el concepto de matronazgo.

${ }^{8}$ Don Luis de la Cerda, I duque de Medinaceli, suegro de María de la Cerda era nieto del marqués de Santillana y sobrino carnal del Gran Cardenal. Incluso una hija del duque, Leonor de la Cerda, contrajo matrimonio con don Rodrigo Díaz de Vivar, marqués de Cenete, hijo del citado cardenal.
DOÑA MARÍA DE SILVA Y TOLEDO Y LA DEVOCIÓN FRANCISCANA DE LA CASA DE SILVA

"Doña María de Silva, hija segunda, (III conde de Cifuentes) nació el año de mil quatrocientos y noventa y quatro, y la adornaron singulares prendas de hermosura, discreción, y prudencia, con que más que sus hermanas, se adelantó en el amor de sus padres" ${ }^{\prime \prime}$.

Con estas palabras el príncipe de los genealogistas, Luis de Salazar y Castro (Valladolid 1658-Madrid 1734), Comendador de Zorita en la Orden de Calatrava y cronista mayor de las Indias, se refería a la quinta hija de los seis vástagos habidos en el matrimonio entre don Juan de Silva, III conde de Cifuentes, y la condesa doña Catalina de Tole$\mathrm{do}^{10}$, hija de los primeros duques de Alba, es decir, doña María de Silva (1494-1544)“una de las señoras de más prudencia y valor de su tiempo"11 (Fig.1).

Doña María de Silva contrajo matrimonio en el año de 1512 con don Juan de la Cerda (1485-1544) ${ }^{12}$, II duque de Medinace-

${ }^{9}$ L. SALAZAR Y CASTRO, Historia de la Casa de Silva. Primera Parte, Madrid, 1685, pp. 324-325. Los paréntesis son nuestros.

${ }^{10}$ Don Alonso de Silva, el primogénito, fue page del malogrado príncipe don Juan, hijo de los Reyes Católicos, fallecido en el año de 1512. Don Fernando, que heredó el título de IV conde de Cifuentes, y se casó con doña Catalina de Andrade y Zúñiga, fallecido en 1545. Don Juan, caballero de la Orden de Santiago, fallecido en 1521. Doña Isabel de Silva, la mayor de las hijas, destacó por su piedad y recogimiento. Doña María de Silva, nuestra protagonista y doña Catalina de Silva, la pequeña de la saga que fue la tercera mujer de don Pedro Fajardo, I marqués de los Vélez.

${ }^{11}$ Real Academia de la Historia (en adelante RAH). Colección Salazar y Castro, 9/293, fol. 57r.

${ }^{12}$ De acuerdo con Salazar y Castro el matrimonio se lleva a término pocos meses después de la muerte del III conde de Cifuentes, que tuvo lugar el 12 de febrero, $\mathrm{y}$ antes del 12 de agosto, fecha en la que su hermano, el IV conde de Cifuentes, obtuvo permiso del rey don Fernando para poder empeñar o vender 100.000 maravedíes de juro de su mayorazgo por hallarse muy endeudado, entre otras, por la dote que le había dado para 


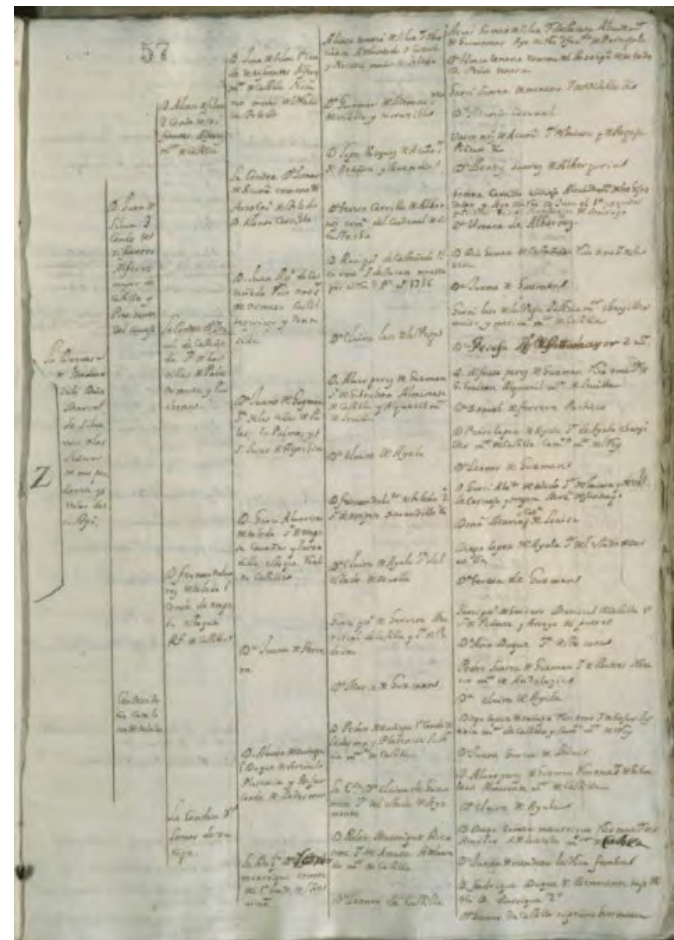

- Fig. 1. Real Academia de la Historia. 9/293, fol. 57r. L. SALAZAR Y CASTRO, Historia de la Casa de Silva. Primera Parte, Madrid, 1685. Costados de doña María de Silva y Toledo. Foto Real Academia de la Historia.

li e hijo natural del I duque de Medinaceli, convirtiéndose en la segunda mujer de este noble portuense quien, en primeras nupcias, se había desposado con doña Mencía Manuel de Portugal (1480-1504)“ generosa e de ilustre prosapia"13, hija de los I condes de Faro y II condes de Odemira y Aveiro, resultando de esta unión tres hijos, a saber: Isabel, Luis y Gastón de la Cerda ${ }^{14}$. A ellos se uni-

su casamiento. Cfr. L. SALAZAR Y CASTRO, Op.cit., p. 325.

${ }^{13}$ G. FERNÁNDEZ DE OVIEDO, Batallas y Quincuagenas, t. I, Madrid, 1983, p. 78.

${ }^{14}$ Previamente la reina Isabel había propuesto con insistencia a Don Luis de la Cerda, I Duque de Medinaceli, tras quedar viudo de Ana de Aragón, que casara con Mencía Manuel. Como este matrimonio no se llevó a cabo, el I duque vio después la posibilidad de que fuese su hijo, el II duque de Medinaceli, el candidato para conseguir la aquiescencia de la Reina Católica a su legitimación y garantizar así la sucesión de éste en el Ducado de Medinaceli, como así fue. Cfr. A. SÁNCHEZ GONZÁLEZ, Medinaceli y Colón. El Puerto de Santa Ma- rían los cuatro habidos en el segundo matrimonio, nacidos entre 1513 y 1523, es decir, Catalina, Juan, Fernando y Luisa. A pesar de que el duque era casi diez años mayor que doña María, ambos fallecieron en 1544, el 20 de enero y el 6 de agosto, respectivamente, siendo enterrados en la capilla mayor del monasterio de Santa María de Huerta, panteón familiar de la casa de La Cerda.

Los miembros de la casa de Silva demostraron afecto y devoción a la religiosidad franciscana ${ }^{15}$. En 1484, previa licencia del papa Urbano VIII, don Juan de Silva, III conde de Cifuentes, fundaba y dotaba un convento, bajo la advocación de la Cruz, en la villa de Cifuentes ${ }^{16}$. Salazar y Castro señala que siguiendo la devoción que sus padres y abuelos habían tenido a dicho convento, don Fernando, IV conde de Cifuentes "fabricó a su costa los claustros alto y baxo, labró la enfermería e hizo cercar dos veces la huerta, mirando con tanta atención aquella casa, que él, por sus mismas manos, plantó muchos "árboles en la huerta. Hizo otros edificios y mejoras en la casa e iglesia, y por su testamento le dexo cien fanegas de trigo, veynte de cevada quince arrobas de aceyte, çinquenta de vino y seis ducados para un puerco $[\ldots]^{\prime \prime 17}$.

Como vemos, el IV conde de Cifuentes don Fernando, hermano de doña María, no sólo amplió el edificio sino que hizo traer desde Italia un retablo para el altar mayor

ría como alternativa del viaje del Descubrimiento, El Puerto de Santa María, 2006, pp. 299 y siguientes.

${ }^{15}$ La devoción franciscana estaba bastante extendida en tierras de la Alcarria. En este sentido, cabe recordar cómo en Guadalajara los miembros de la Casa del Infantado convirtieron la iglesia de San Francisco en panteón familiar. En general, todos los miembros de la familia Mendoza hicieron fundaciones franciscanas y cerca de Cifuentes, entre Tendilla y Peñalver, se localizaba el monasterio franciscano de La Salceda, con el que tuvieron relación algunos miembros de la estirpe mendocina.

${ }^{16}$ A. HERRERA CASADO, Monasterios y conventos de la provincia de Guadalajara, Guadalajara, 1974.

${ }^{17}$ L. SALAZAR Y CASTRO, Op.cit. pp. 342-344. 
de la iglesia del monasterio ${ }^{18}$. Por otro lado, consta que fundó en la misma villa un monasterio de religiosas de la Orden de San Francisco al que llamó Nuestra Señora de Belén y unido a él un Colegio de doncellas ${ }^{19}$.

La devoción por la orden seráfica debió ser un sello de distinción de la familia Silva, pues la hija y hermana del II y III conde Cifuentes, respectivamente, doña María de Silva, fundó en la villa de Medinaceli dos monasterios vinculados con esta religión. Obviamente, contaba con el apoyo de su marido, don Juan de la Cerda, II duque de Medinaceli, quien ya había fundado en 1504 en El Puerto de Santa María, junto a su primera mujer, un monasterio dedicado a los Mínimos de San Francisco de Paula, bajo la advocación de la virgen de la Victoria ${ }^{20}$. Obviamente, su creación debe entenderse en el contexto de engrandecer y dotar a la villa cabecera del ducado de una imagen de exaltación del poder nobiliario. En este sentido, el II duque había terminado de construir la iglesia de Santa María, iniciada por su padre, don Luis de la Cerda, y comenzado la construcción de un palacio cuya fachada se abría a una plaza en la que se ubicaban otros destacados edificios civiles ${ }^{21}$. El deseo de expresar el poder a través de la arquitectura y el urbanismo era más que notorio, creando una nueva imagen del

${ }^{18}$ Este dato es aportado por Teresa Díaz pero ignoramos de dónde extrae la noticia pues no cita ninguna referencia. T. DÍAZ DÍAZ, "Hospitales del Remedio y del Socorro: dos instituciones benéficas desaparecidas en Cifuentes (Guadalajara)", en La iglesia española y las instituciones de Caridad, Madrid, 2006, p. 652.

${ }^{19}$ L.SALAZAR Y CASTRO, Op.cit. p. 342.

${ }^{20}$ Una puesta a punto en la tesis doctoral que se mantiene inédita de R. ROMERO MEDINA, Arquitectura Medieval en El Puerto de Santa María. Del Islam al inicio del Renacimiento, Tesis doctoral defendida en la Universidad de Cádiz, 2009.

${ }^{21}$ Sobre la iglesia véase ÍDEM, "El taller de entalladores alcarreños de Lorenzo Vázquez y el retablo de la iglesia de Santa María de Medinaceli", Boletín del Museo e Instituto Camón Aznar, no 103, 2009, pp. 35-62. centro del dominio aristocrático de los de La Cerda ${ }^{22}$.

La primera fundación tuvo lugar en 1527, “a un cuarto de legua de la dicha villa" ${ }^{23}$, y se trató de un monasterio, dedicado a San Francisco, que recibió el provincial de Castilla fray Diego Cisneros. De él no se conservan restos, a pesar de que el edificio fue traslado posteriormente al interior de la villa, cerca del arco romano, aunque sí descripciones como las de Baltasar Porreño, que señala cómo "los duques tienen en él unos famosos aposentos con un oratorio que sale a la capilla mayor, donde se retiran las Semanas Santas y otras ocasiones"24; incluso se alude a su dotación con una librería con ejemplares de diversa índole.

La segunda fundación se produjo un año después, en 1528, y en esta ocasión era un monasterio de monjas franciscanas de Santa Clara bajo la advocación de Santa Isabel. Como ahora analizaremos, esta fue fruto del desvelo de la duquesa doña María de Silva y Toledo quien trajo incluso a las primeras monjas del monasterio de Santa Isabel de Toledo para poner en marcha la primera comunidad tras obtener la debida licencia.

${ }^{22}$ En este sentido, no debemos de olvidar que don Juan de la Cerda era hijo de Catalina Vique de Orejón o del Puerto, una mujer que no pertenecía a la nobleza, y que su legitimación como sucesor en la casa y estados de Medinaceli se produjo por parte de los Reyes Católicos.y por deseo de su padre, don Luis de la Cerda, I duque de dicho título. Las fundaciones de su mujer doña María de Silva en la villa de Medinaceli fueron una manera de ligar la casa de Medinaceli con las tradiciones de la casa de Silva y colocar a los duques de Medinaceli en la cabeza del ducado para reforzar esta idea de legitimidad.

${ }^{23}$ Incluso se señala que fue fundado en la ladera de la montaña al mediodía evitando así el frío, por la latitud en la que se ubica la villa, "donde hace tan diferente temple que parece estar en otra región". Cit. B. PORRENO, "Elogios de los ínclitos condes y excelentísimos duques de la gran Casa de Medinaceli", en A. PAZ Y MELIA, Serie de los más importantes documentos del archivo y biblioteca del Excelentísimo señor duque de Medinaceli, Madrid, 1915.

${ }^{24}$ B. PORREÑN, Op.cit. 
DATOS SOBRE LA FUNDACIÓN DE MONJAS FRANCISCANAS DE SANTA CLARA, CONVENTO DE SANTA ISABEL DE MEDINACELI

El 4 de julio de 1517 se asentaba escritura de compraventa ante Íñigo de Tolosa entre Gil de Andrade, señor de Sotillo y Moranchel, y su mujer, Juana de Castilla, con doña María de Silva, en la que estos vendían a la duquesa de Medinaceli unas casas por valor de 436.428 maravedíes $^{25}$. Las casas, ubicadas en el barrio de San Martín de la villa de Medinaceli, tenían "por aledaños de todas partes hazia la parte de Sant Martin la calle que esta e va en las dichas casas e la dicha yglesia de San Martin e por la otra la calle que va entre las dichas casas y casas de Francisço de Esquivel vezino de la dicha villa e por la delantera el campo e plaça que es e se dize de San Nicolas e por las espaldas el campo frontero de San Roman todas de alto e baxo e con su huerta e corrales e pozos y algibes $[\ldots]^{\prime 26}$.

Estas casas fueron las destinadas a la fundación del monasterio y dado que la duquesa las había comprado durante su matrimonio y, por tanto, eran bienes gananciales, el 9 de julio de 1526, su marido, don Juan de la Cerda, renunciaba a ellas haciéndole donación "pura, perfecta e non revocable"27. Del mismo modo, el duque le hacía donación de cuatro sayas de brocado, junto a otros atavíos, cosas y joyas que entendemos iba a destinar a la dicha fundación conventual.

El 7 de agosto de 1526 se llegaba al primer acuerdo entre doña María de Silva y el ministro provincial de Castilla ${ }^{28}$, Fray Diego

\footnotetext{
${ }^{25}$ Archivo Ducal de Medinaceli (en adelante ADM), Sección Medinaceli. Legajo 23, no 1 .

${ }^{26}$ Ibídem.

${ }^{27}$ Ibídem, no 2 .

${ }^{28} \mathrm{El}$ proceso de negociación pudo dilatarse, pues no sabemos qué pudo ocurrir en el lapso de tiempo que va desde la compra de las casas, en 1517, a los primeros acuerdos en 1526. Estamos hablando de un período de casi diez años.
}

de Cisneros, para la fundación del monasterio de religiosas franciscanas de Santa Clara, bajo la advocación de Santa Isabel, en la villa ducal de Medinaceli ${ }^{29}$. En el mismo la duquesa donaba las casas junto a San Martín para servir de cobijo a la comunidad y para hacer el torno y locutorio, junto a veinte mil maravedíes anuales para el mantenimiento de la dicha comunidad ${ }^{30}$.

El 1 de enero de $1528^{31}$ la donación se hacía efectiva y la duquesa doña María de Silva prometía los veinte mil maravedíes de renta anuales, más trescientas cabezas de ganado lanar, veinte fanegas anuales de sal de las salinas del ducado de Medinaceli y se comprometía a edificar a su costa el coro entre la iglesia de San Martín y el monasterio, un refectorio y otras estancias necesarias, así como acrecentar la tapia de la huerta, dándole una mayor altura ${ }^{32}$. Ese mismo día, Fray Diego de Cisneros autorizaba mediante licencia la dicha fundación y las religiosas que hizo venir la duquesa del monasterio de Santa Isabel de Toledo, a saber: Isabel de Toledo (su prima e hija del conde de Oropesa), como abadesa, Aldonza Pantoja, Juana Mejía y Catalina Suárez, ofrecían obediencia al provincial franciscano ${ }^{33}$.

Finalmente, el 13 de febrero de 1528, el vicario general del obispado de Sigüenza, Antonio Mora, daba licencia a la duquesa doña María de Silva para que pudiese anexionar la iglesia de San Martín junto a un pedazo de tierra aledaño ${ }^{34}$. En este sentido, las intenciones de la duquesa no eran otras que las de hacer un edificio más amplio. Con ello, las casas en las que se había fundado el monasterio quedaban unidas a la iglesia de

\footnotetext{
${ }^{29}$ ADM, Sección Medinaceli, Legajo 23, nº 3.

${ }^{30}$ Ibídem.

${ }^{31}$ Tampoco disponemos de noticias de los dos años transcurridos entre 1526 y 1528, es decir, desde que se llega a los primeros acuerdos hasta que la donación se hace efectiva.

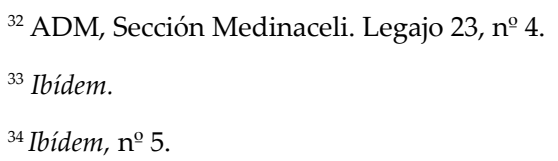


San Martín mediante la construcción de un coro que se hizo a costa de la vía pública.

Consta que se debieron tomar otras casas para la ampliación del solar cuya tasación se estableció en 51.500 maravedíes $^{35}$. Del mismo modo, se tasó el despojo, es decir, los materiales que se podían aprovechar de estos derribos, en 13.325 maravedíes.

Así, comenzaba a funcionar una comunidad franciscana de clarisas que tuvo un papel importante como centro dinamizador de la espiritualidad en la villa de Medinaceli durante los siglos de la Edad Moderna ${ }^{36}$.

\section{DATOS SOBRE LA OBRA DE CANTE- RÍA: EL MAESTRO JUAN VÉLEZ}

Como hemos señalado, la compra de casas en 1517 es un gesto que, con independencia de los trámites para la fundación, denota la elección del terreno para la obra. Del mismo modo, había que pensar en el tracista del monasterio y en posibles maestros para su ejecución. En esa fecha, el arquitecto vinculado a los Medinaceli, Lorenzo Vázquez ${ }^{37}$, ya había fallecido, pero su presencia constante en la villa soriana permite pensar en algún maestro de su círculo. Sea como fuere, este proceso debió depender de doña María de Silva, pues la documentación de la obra le da un papel muy destacado, aunque sobre el posible autor de la traza trataremos más adelante.

No sabemos si las obras pudieron iniciarse antes, pues la documentación conservada corresponde a los años de 1529 y 1530

\footnotetext{
${ }^{35}$ Ibídem, no ${ }^{\circ}$. Las casas fueron las de Miguel López, Pedro Hernando, Juan de Anes, Juan Hernando, Sebastián Hernando y Martín de la Casa.

${ }^{36}$ Sobre la historia de este convento puede consultarse el único trabajo que existe hasta el momento de J.A. MÁRQUEZ MUÑOZ, “Santa Isabel de Medinaceli. Un convento de clarisas en la villa ducal, desde 1528", Celtiberia, no 71,1986 , pp. 153-166.

${ }^{37}$ R. ROMERO MEDINA, “La arquitectura en época de los Reyes Católicos. Lorenzo Vázquez de Segovia introductor del renacimiento en Castilla (C.1450-1515)", Anuario Científico Isabel I, 1, 2013, pp. 479-498.
}

en la que se localizan condiciones, tasaciones y concierto de obras en el edificio. En este sentido, Juan Vélez es uno de los maestros del que se tiene noticia y al que se le deben las obras de cantería realizadas en el monasterio. Este maestro está relacionado con el círculo de cantería de Sigüenza, obispado al que pertenecía Medinaceli, y con la figura del maestro Alonso de Covarrubias, al que luego nos referiremos ${ }^{38}$. La hipótesis de este maestro como autor de la traza es una de las posibilidades que barajamos, teniendo en cuenta que el maestro toledano había trabajado para otras mujeres nobles del círculo de doña María de Silva.

Los primeros datos de Juan Vélez fueron dados a conocer por Román Andrés de la Pastora quien le atribuye la autoría del coro de la iglesia de Santiuste en Medinaceli, construido en el año de 1530, el coro de la iglesia de San Gil de la misma villa, por el que cobraría la cifra de 10.125 maravedíes, en 1538, y la cabecera de esta iglesia, construida entre 1553 y 1554, por la que recibía la cifra de 300.000 maravedíes $^{39}$. Estos datos no han podido ser contrastados y deben ser sometidos a revisión si tenemos en cuenta que la mayor parte de estos templos fueron demolidos en el siglo XVI y eran fábricas tan pobres que, como señala Rabal, "en algunas se bautizaba en una caldera por no haber di-

\footnotetext{
${ }^{38}$ En este sentido, Muñoz Jiménez lo relaciona en su etapa de madurez con obras cercanas al manierismo de Serlio, próximo a las últimas obras de Covarrubias, y lo data como maestro de obras y tracista de la girola de la catedral de Sigüenza hacia 1569. Cfr. J. M. MUÑOZ JIMÉNEZ La arquitectura del manierismo en Guadalajara, Guadalajara, 1987, pp. 492 y siguientes. Con posterioridad, amplía las noticias documentales del maestro y le atribuye la iglesia del monasterio de Óvila, obra en la que se ocupa entre 1554 y 1569. ÍDEM, “El manierismo seguntino: la creciente importancia del arquitecto Juan Vélez", Anales Seguntinos, no 5, 1988, pp. 191-206. Por último, le atribuye otras obras y lo relaciona con maestros como Juan del Pozo. ÍDEM, "La arquitectura del plateresco en la provincia de Guadalajara (1492-1550)", Wad al Hayara, Revista de estudios de Guadalajara, 21, 1994, pp. 141-179.

${ }^{39}$ R.A. DE LA PASTORA, Papeletas históricas inéditas en el archivo de Sigüenza. Catedral de Sigüenza, s/f.
} 
nero para fabricar una pila de piedra" ${ }^{40}$. Lo importante es que queda demostrada su vinculación con la villa de Medinaceli a través de las obras de Santa Isabel.

El 9 de agosto de 1529 el maestro Juan Vélez se comprometía a realizar, en un plazo de cuarenta días, el espacio del refectorio sobre ciertos terrenos de la huerta que lindaban con el monasterio, pues "debía hacer las tres paredes que está sobre la huerta con sus vueltas juntas las paredes con la mesma casa" $^{41}$. La fábrica debía de ser funcional, utilizando la piedra de la huerta a poder ser e incluso los esquinares labrados que habían sobrado de otra obra, con paredes de dos pies de vara real de grueso y con ventanas toscas, es decir, sin ningún tipo de concesión a la decoración. El maestro se comprometía si no a traer la piedra a su costa y corría de su parte la cal, el agua y la arena, siendo la madera el único material proporcionado por el mayordomo de la obra ${ }^{42}$.

En la tasación final el valor de la estancia del refectorio se calculó en 130.000 maravedíes, pues no sólo se tuvo en cuenta la obra de cal y canto sino las armaduras de madera, con tejados y tejaroces, las ventanas de madera y las rejas de hierro, así como la puerta y paso a la clausura y la ventana y servicio de la cocina ${ }^{43}$.

En este mismo año de 1529 el maestro Juan Vélez ofrecía una tasación con los costes $\mathrm{y}$ pormenores que implicaban, mayoritaria-

${ }^{40}$ N. RABAL, Soria. Sus monumentos y Artes. Su naturaleza e Historia, Barcelona, 1889, p. 407.

${ }^{41}$ Cfr. ADM, Sección Medinaceli, Legajo 23, no 6 .

${ }^{42}$ En total el maestro se comprometía a realizar 65 tapias a precio cada tapia de 450 maravedíes, por lo que el montante, librado en tercios de 9.750 maravedíes, ascendía a 29.250 maravedíes. No obstante, en un documento posterior se citan la cantidad de 99 tapias en esta primera tasación con lo que la cifra ascendía a 44.775 maravedíes. A ello había que sumar 18.775 por otras 40.5 tapias que se hicieron de más dentro del monasterio. Por ello, el montante que el maestro recibió en concepto de fabricación de tapias fue de 63.550 maravedíes. Cfr, Ibídem.

${ }^{43}$ Ibídem.

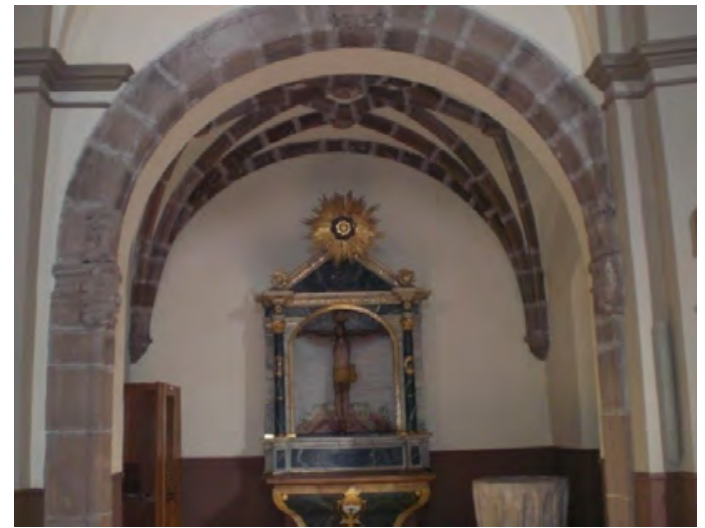

- Fig. 2. Iglesia del monasterio de Santa Isabel de Medinaceli. Capilla del evangelio. Foto del autor.

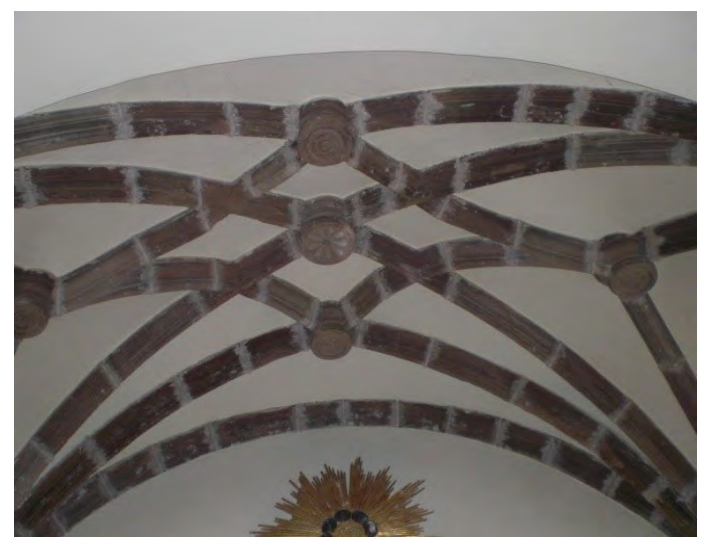

- Fig. 3. Iglesia del monasterio de Santa Isabel de Medinaceli. Bóveda de la capilla del evangelio. Foto del autor.

mente, las obras en la iglesia del monasterio. No debemos olvidar que para la iglesia del convento se aprovechó la antigua parroquia de San Martín, por lo que había que realizar ciertas reformas. El documento nos ofrece detalles que nos permite conocer cómo era la obra original de la que solo subsiste una capilla levantada en el lado del evangelio, ya que la nave y la capilla mayor fueron reedificadas a mediados del siglo XVIII. La capilla original se abre a la nave con arco de medio punto que apea sobre pilastras toscanas, cuyos capiteles y clave del arco llevan escudos timbrados $^{44}$ (Figs. 2-5). Se cubre con bóveda de crucería con nervios combados y forma

\footnotetext{
${ }^{44}$ Incluso se observa cómo el escudo situado sobre el capitel de la columna toscana a la derecha de la capilla quedó seccionado con las reformas que se hicieron en la iglesia hacia el siglo XVIII, las cuales, como hemos
} 


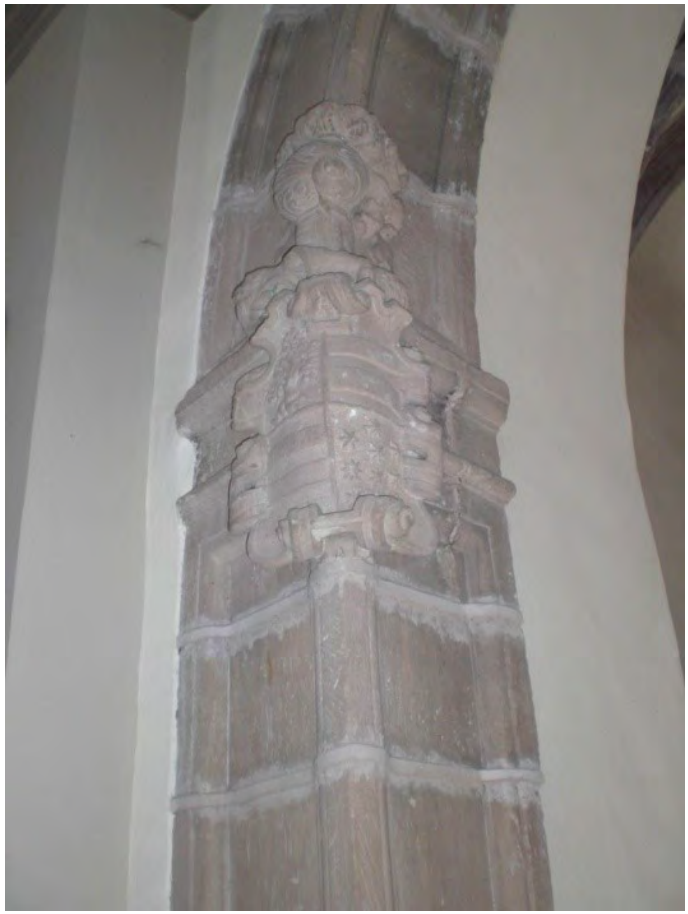

- Fig. 4. Iglesia del monasterio de Santa Isabel de Medinaceli. Detalle del pilar toscano y escudo timbrado. Foto del autor.

romboidal y claves ornadas. Los nervios mueren en unas ménsulas angulares de corte renacentista. Estamos ante una construcción tardogótica con la hibridación de lenguajes arquitectónicos del momento. La obra se encuentra en sintonía con la iglesia del monasterio de Óvila, atribuida al maestro Vélez, en la que nos encontramos con orden toscano en las pilastras de las que arrancan arcos apuntados, o con el primer diseño para el deambulatorio de la catedral de Sigüenza, que llevaba bóvedas de crucería ${ }^{45}$.

En la iglesia había que realizar ciertas obras en la cabecera en la que se debía hacer un arco "de la una pared a la otra que sea a flor de tierra y este arco ha de ser tosco para que reciba una pared por donde agora está el altar mayor para que salga la capilla en quadrado" ${ }^{\prime 46}$. Del mismo modo, había que subir la pared

señalado, transformaron por completo la nave y la cabecera de la iglesia. Vid. Fig. 5.

\footnotetext{
${ }^{45}$ Cfr. J.M. MUÑOZ JIMÉNEZ, Arquitectura del plateresco..., pp.161-162.
}

${ }^{46}$ ADM, Sección Medinaceli, Legajo 23, nº 6 .

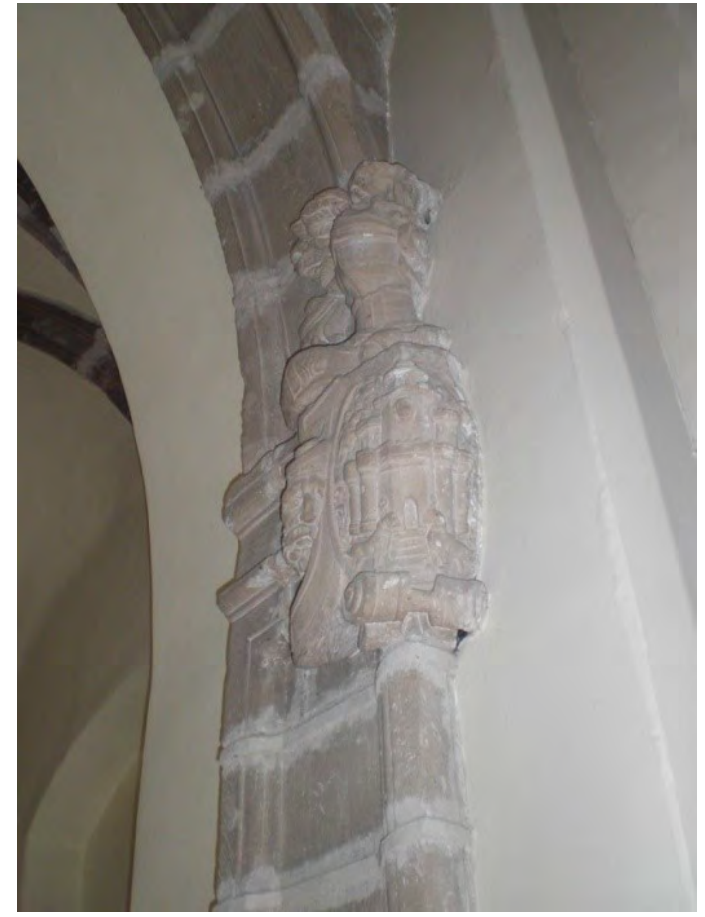

- Fig. 5. Iglesia del monasterio de Santa Isabel de Medinaceli. Detalle del pilar toscano y escudo timbrado seccionado. Foto del autor.

de cal y canto hasta la bóveda "y enluzida de yeso y careada conforme a la capilla y a dese rasgar una ventana porque la que ahora está hecha se cierra con la dicha pared" ${ }^{\prime 4}$. Obviamente, la remodelación de la capilla, que debía separarse de la nave por una grada, pasaba por la construcción de un nuevo altar mayor con mesa de tres gradas, todo de piedra de buena labra, por lo que incrementaba el precio en 6.500 maravedíes más. Del mismo modo, había que hacer de nuevo el tejado de toda la capilla mayor "quitando la tierra que agora esta encima porque se le llueve y daña toda la boveda" ${ }^{\prime 8}$ y rematar el tejaroz de piedra, por precio de 1.485 maravedíes. Reforzando la idea de remodelación, la documentación insiste en reaprovechar materiales existentes "y si alguna piedra hubiere por allí que las tome de las que quytare del campanario" ${ }^{\prime \prime 9}$.

${ }^{47} \mathrm{Ibídem}$. El maestro estimaba esta obra en 6.000 maravedíes, aunque sin la ventana la obra se abarataba en 1.000 maravedies.

${ }^{48}$ Ibídem.

${ }^{49}$ Ibídem. 
Por último, se alude a la construcción de dos altares pequeños a la entrada de la capi1la "en el rincón de los pies derechos del arco principal" ${ }^{50}$ que debían de hacerse en sillería con seis pies de largo y con su mesa llana de piedra en el suelo "y encima del mesmo altar dos piezas grandes de piedra con una copada muy bien labrada en la delantera y al un costado que vuele de cada parte medio

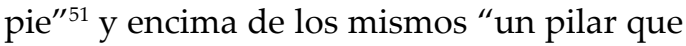
suba quatro pies o quatro y medio murtido y con su remate muy bien labrado" 52 . El mayordomo estipulaba que estos altares debían quedar dentro de la capilla como en la iglesia de San Francisco de Medinaceli, aunque Vélez señalaba que no era posible porque al medir seis pies y medio de largo, tomando la referencia de esta medida en cada lado, el espacio de subida al altar mayor quedaba muy reducido, por lo que había que realizarlos en la entrada de la capilla junto al arco.

Otra intervención importante se debía de realizar en el coro cuya pared era de yeso y el mayordomo pidió que "el arco llano a la parte de fuera" 53 fuese "sin escaçan". Entendemos que se refiere a un tipo de refuerzo o arco escarzano que era rebajado y formado por un segmento circular menor que la circunferencia de forma que el centro está por debajo de la línea de impostas y las tangentes en los arranques son inclinadas. Sin el retundido, es decir, el acabado final del paramento, la obra ascendía a 28.700 maravedíes. La obra del coro se hizo a costa de una vía pública y ello permitió unir la iglesia a las estancias del convento. En la tasación final la obra del coro se valoró en 138.400 maravedíes, en la que se incluía el acabado de cal y canto, las armaduras de madera toscas y labradas con su tejados y tejaroces, ventanas y puertas, incluidas las cerraduras del coro y del confesionario.

La portada de la iglesia, hoy en día transformada por las reformas del siglo XVIII, es-

\footnotetext{
${ }^{50}$ Ibídem.

${ }^{51}$ Ibídem.

${ }^{52}$ Ibídem.

${ }^{53}$ Ibídem.
}

taba casi en ruina, se habla de "descalzada", y había que rehacerla de buena piedra y bien labrada siendo reforzada al interior con un arco escarzano. La obra ascendía a 7.500 maravedíes. Se conserva el contrato para la ejecución de la misma que fue concertado ante el escribano Juan de Villena por Juan Vélez y el mayordomo, Miguel Zoyo, el 2 de marzo de 1530.

Por último era necesario igualar todo el muro perimetral de la iglesia "retundiendo e revocando" toda su superficie restituyendo los sillares que se encontrasen en mal estado. Del mismo modo se alude a la necesidad de echar canes y entablamentos en una zona caída junto al aposento de los frailes " y si acaso quisyere que no se retunda sy no que se reboque y sosaçar y enrase muy bien y echen los canes y entablamentos como dicho es" ${ }^{\prime \prime 4}$.

El aposento de los frailes debió ser un cuarto, pieza o habitación destinado a dar posada a los religiosos que asistían la comunidad de clarisas, que se realizó "conforme a las condiciones y traça" y cuyo valor se estimó en 50.000 maravedíes. El documento estipula que dicho aposento no debía disponer de reja de hierro.

La documentación alude a la realización de un portal y entendemos que se trataba de una especie de pórtico o claustro que, partiendo de la puerta de la iglesia, unía el aposento de los frailes con la sacristía. Obviamente, cumplía la función de servir de resguardo ante las inclemencias del tiempo. Esta suerte de galería se debía de hacer con pilares de piedra de granito, con sus basas y capiteles, de la cantera de Miño, e iba con una cubierta de madera "con sus vygas y analas e con sus cuartones e tablas açepilladas y en colgadizo con sus soleras y tabicas y los cuartones con trechos muy bien encadenados y trabados con yeso en la pared $[\ldots]^{\prime \prime 55}$ señalándose, incluso, que "por la parte de fuera su ala despierta de argallones

\footnotetext{
${ }^{54}$ Ibídem.

${ }^{55}$ Ibídem.
} 
y tablas" ${ }^{56}$. Ello tenía un coste de 13.000 maravedíes.

Finalmente se recogen otros pagos relativos a la obra de la cerca de la huerta que se labró de cal y canto "conforme a las condiciones y traza" por precio de 40.000 maravedíes. Del mismo modo, se alude a la construcción de las "necesarias", es decir, las letrinas ubicadas en el antepaso al dormitorio "que baxe a ella con cuatroçientos escalones porque no sean tan altas" ${ }^{\prime \prime 7}$ cuya construcción tenían un valor de 12.000 maravedíes. Incluso se alude al sistema de canalización de las necesarias que debía pasar por el dormitorio del convento y hacerlas llevar hacia la huerta "armado sobre cancas de madera y teja" 58 por valor de 3.750 maravedíes.

\section{DATOS SOBRE LOS FORJADOS DE MADERA DE PISO DECORADOS: JUAN DE CARASA Y ALONSO DE COVARRUBIAS}

Las estancias del monasterio estuvieron dotadas de una forma de cubrir sus espacios con forjados de piso de madera, algo frecuente en la arquitectura del tardogótico castellano, entre los que destacó el alfarje de cinta y saetino de gran vistosidad porque eran decorados con frisos corridos de ménsulas que se policromaban.

En 1529 el maestro Juan de Carasa, vecino de Sigüenza, presentaba ciertas condiciones por las que se comprometía a realizar el suelo alto del dormitorio que, aunque apreciaba en 68.000 maravedíes, ofrecía a la duquesa por 10.000 maravedíes a la baja, es decir, 58.000 maravedíes que debían librarse por tercios ${ }^{59}$. El apellido de este maestro denota un origen trasmerano y debe ser familiar del entallador Fernando de Carasa documentado en 1528 como autor de las

\footnotetext{
${ }^{56}$ Ibídem.

${ }^{57}$ Ibídem.

${ }^{58}$ Ibídem.

${ }^{59}$ Ibídem.
}

puertas de los órganos grandes y pequeños de la catedral de Sigüenza ${ }^{60}$. Su presencia es documentada con posterioridad, entre 1533 y 1534, en las obras de la plaza mayor de Sigüenza cuando se le tomaron en cuenta al mayordomo del cabildo "quatorzemill e seyçientos y çinquenta maravedís que dio a Juan de Carasa para en señal de la madera que se a de gastar en las casas de la plaça" ${ }^{61}$.

De las condiciones presentadas por Juan de Carasa y de la tasación que, el 8 de noviembre de 1529, realizaron Hernando de Camino, veedor de la obra del duque de Medinaceli, Pedro de la Riba y maestre Andrés, de los trabajos de carpintería realizados por el maestro trasmerano, podemos extraer ciertas conclusiones sobre los forjados de madera que se realizaron en el suelo alto del citado dormitorio, junto con sus puertas y ventanas ${ }^{62}$.

El suelo alto se iba a ejecutar con una solución clásica de carpintería de armar española, como se desprende de las escuadrías de las piezas descritas en la documentación. El piso con solución de cintas y saetino se resolvía mediante el uso de cuartones, llamadas alfargías, que sostenían las tablas o tabletas dispuestas de forma perpendicular a los cuartones. En este sentido, las juntas de las tablas y la parte superior de los cuartones se resolvían con unos listones. Los aliceres eran las piezas que se disponían en las cabezas de dichos cuartones. Tanto las cintas como los saetinos tenían perfil achaflanado y ello obligaba a que todos los encuentros tuviesen que ser cortados a inglete, lo que condicionaba que la longitud de cada saetino fuese mayor que la distancia entre las cintas ${ }^{63}$. Para rematar la

${ }^{60}$ A. ÁVILA PADRÓN y J. ROGELIO BUENDÍA, "Datos sobre la música del Renacimiento en la catedral de Sigüenza. Mateo Flecha el Viejo y Hernando de Cabezón", Recerca Musicológica, 1, 1981, p. 196.

${ }^{61}$ Cit. P. MARTÍNEZ TABOADA, "Fuentes documentales de archivo para el estudio de los arquitectos y maestros que diseñaron y construyeron la plaza mayor de Sigüenza", Anales de Historia del Arte, 14, 2004, p.77.

${ }^{62}$ ADM, Sección Medinaceli, Legajo 23, ㄲo 6.

${ }^{63}$ Enrique Nuere hace un pormenorizado estudio sobre estas estructuras y sus singularidades en E. NUERE 
estructura, sobre las tablas se colocaba una alcatifa y un solado de barro y, por la presencia de partidas de yeso en la documentación, pensamos que tuvo una moldura corrida por la parte inferior de los cuartos o alfargias a modo de arrocabe. La presencia del término "moldura romana muy bien moldada" nos indica que esta estructura era de estilo renacentista.

Un dato descriptivo que aporta la documentación nos pone sobre la pista de un importante maestro. En este sentido, se alude a que la estructura debía de llevar su caramanchón y tejado "armado con sus tixeras", una techumbre característica formada por elementos triangulares realizados con gruesos maderos. El maestro Juan de Carasa se obligaba a realizarlo "conforme a las condiciones primeras que Alonso de Covarrubias hizo para la dicha obra" ${ }^{\prime 64}$.

Efectivamente la documentación alude al maestro toledano Alonso de Covarrubias quien debió de dar ciertas condiciones o, por qué no, las condiciones para esta obra. Su formación inicial como entallador le capacitaba plenamente para su ejecución en unos momentos en los que trabajaba como tracista y maestro de obras en solitario en tierras de la Alcarria. La documentación señala que el maestro estaba obligado a realizar "setenta pies del dicho tejado" poniendo a su costa toda la madera, yeso, cal, arena y clavazón.

Así las cosas, queda probada la presencia del maestro en las obras de Medinaceli, en unos momentos en los que trabajaba en Sigüenza a cuyo obispado pertenecía la villa ducal. Este será el modus operandi que en 1549 emplee en el palacio ducal de Pastrana, cuando Justo de Vega y Cristobal de Nieva eran contratados para hacer el maderaje del zagúan y salas superiores, según las condiciones dadas por el maestro toledano ${ }^{65}$.

MATAUCO, La carpintería de armar española, Madrid, 2000.

${ }^{64}$ ADM, Sección Medinaceli, Legajo 23, nº 6 .

${ }^{65}$ A. GARCÍA LOPEZ, "Alonso de Covarrubias autor del palacio ducal de Pastrana. Documentación so-
DISCUSIÓN E HIPÓTESIS SOBRE LA TRAZA DEL MONASTERIO: ¿ALONSO DE COVARRUBIAS?

La documentación conservada sobre las obras en Santa Isabel alude de forma constante a que Juan Vélez debía de ejecutar los trabajos conforme a las condiciones y traza dada. Por tanto, queda claro que este maestro se limitó a ejecutar la obra pero no fue el tracista de la misma. ¿Quién trazó el monasterio?

Se trata de una cuestión ciertamente complicada debido a la ausencia de datos en la documentación, si bien se pueden conjeturar algunas hipótesis. Por un lado, podemos plantear que pueda tratarse de una obra de Alonso de Covarrubias (1488-1580), quien trabajó tempranamente en la catedral de Sigüenza y quien pudo dejar a Juan Vélez como ejecutor material de la obra. Ello lo fundamentamos no sólo en la relación que existió entre ambos maestros, sino porque la documentación deja claro que Covarrubias dio ciertas condiciones para el artesonado del dormitorio del monasterio y realizó parte del tejado. Cabe conjeturar, por tanto, que la traza del edificio, como ocurrió posteriormente con el palacio de Pastrana, se deba a la mano del maestro que pudo desplazarse en determinadas ocasiones a Medinaceli para supervisar la obra.

Por otro lado, cabría la posibilidad que de Covarrubias sólo hubiese dado ciertas condiciones de los forjados de madera del monasterio y que la traza arquitectónica se deba a un maestro del círculo castellano del tardogótico. Si tenemos en cuenta que Lorenzo Vázquez, el maestro de los Medinaceli, ya había fallecido en estos momentos, su presencia activa en la villa invita a pensar que pudo ser un maestro de su círculo.

Aunque Covarrubias se inicie en las obras tardogóticas de Toledo, en esa fecha ya aplicaba los elementos claramente renacentistas, como lo prueba la obra de la fachada del convento de la Piedad de Guadalaja-

bre su construcción de 1542 a 1553", Wad-al-Hayara, 19, 1992, pp. 51-74. 


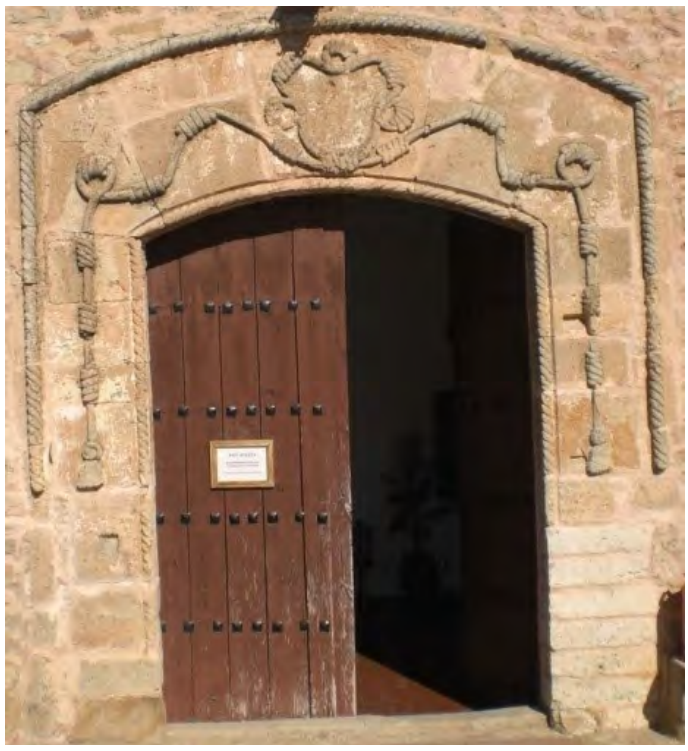

- Fig. 6. Monasterio de Santa Isabel de Medinaceli. Portada tardogótica. Foto del autor.

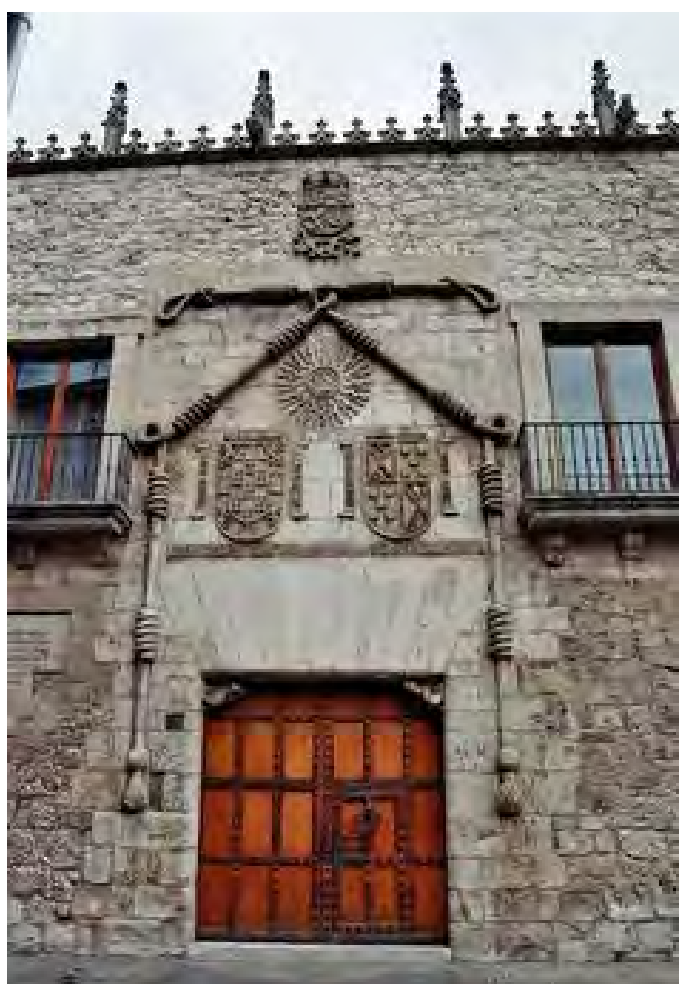

- Fig. 7. Casa del Cordón. Burgos. Foto del autor.

ra, ejecutada entre 1526 y 1529. Del mismo modo, la moldura a la romana que se cita en las condiciones del piso alto del dormitorio, nos habla de una obra "a la antigua". No obstante, la versatilidad entre los lenguajes del último gótico y los renacentistas eran la

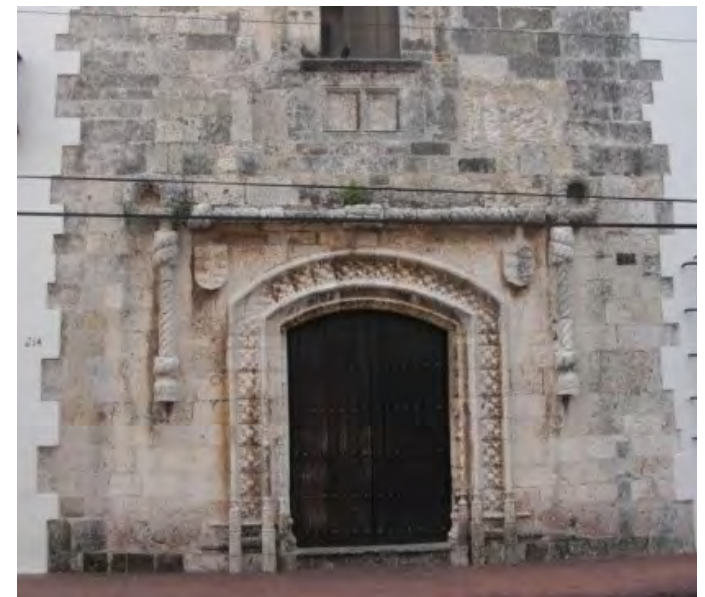

- Fig. 8. Casa del Cordón. Santo Domingo. Foto del autor.

nota de cambio y el maestro los manejaba con soltura, como se desprende de sus posteriores intervenciones en la iglesia del convento de San Francisco de Pastrana o en el palacio de la condesa de Mélito en la misma localidad.

En este sentido, de los pocos elementos originales que se conservan del monasterio de Santa Isabel se encuentra la fachada, que se orienta hacia el mediodía, en la que se ubica una puerta descentrada respecto al eje del edificio, como era habitual en las obras del último gótico, que consta de arco escarzano y cordón franciscano enmarcándola a manera de alfiz, junto a ventanas conopiales y rectangulares colocadas de forma asimétrica (Fig. 6). Como se observa, la referencia a la casa del Cordón de Burgos es más que notable (Fig. 7), pero se trata de un elemento muy extendido en la arquitectura hispánica o incluso en tierras americanas, tal y como se observa en la casa del mismo nombre en la ciudad de Santo Domingo. (Fig. 8).

La atribución de la autoría de la traza a Covarrubias cobra fuerza si analizamos los elementos arquitectónicos conservados en Medinaceli con otras obras suyas cuya mano ha quedado demostrada. A partir de 1520 Alonso de Covarrubias está documentado como tracista, si bien con el maestro Egas o Vasco de la Zarza. Es en esta fecha cuándo, bajo la supervisión de Vasco de la Zarza, da 
la traza para la iglesia del monasterio de San Bartolomé de Lupiana ${ }^{66}$. En 1526 el maestro da en solitario la traza de la iglesia de Albalate de Zorita, en Guadalajara ${ }^{67}$. El modelo de esta construcción combina elementos góticos, como el arco carpanel y/o las bóvedas de crucería, con grutescos, frisos y pilastras. Estos mismos elementos arquitectónicos son visibles en la capilla del evangelio del monasterio de Medinaceli, uno de los pocos elementos originales de la obra, que levanta Juan Vélez.

La utilización de modelos arquitectónicos y decorativos tardogóticos permitirían atribuir la traza del monasterio de Medinaceli a Alonso de Covarrubias, pues coincide con obras de su estilo inicial. En este sentido, 1526 es la fecha en la que María de Silva obtiene los primeros acuerdos para la fundación franciscana femenina y puede barajarse como fecha en la que encargue la traza del proyecto a Covarrubias. Como sostenemos esta obra fue un empeño claro de la duquesa de Medinaceli y debió acudir al maestro que en estos momentos estaba de moda en los círculos sociales femeninos, como lo prueba el hecho de que doña Brianda de Mendoza y Luna, hija del II duque del Infantado, también le encargó la construcción de la iglesia del monasterio de la Piedad en Guadalaja$\mathrm{ra}^{68}$. A falta de nuevos datos, podemos atribuir la traza del monasterio de Santa Isabel de Medinaceli al maestro Covarrubias.
${ }^{66}$ L. ZOLLE BETEGÓN, "El monasterio de San Bartolomé de Lupiana. Precisiones en torno a su construcción (1504-1612)", Archivo Español de Arte, LXIX, 275, 1996, pp. 278 y siguientes.

${ }^{67}$ E. IPIENS MARTÍNEZ, “La construcción de la iglesia de Albalate de Zorita (Guadalajara) con trazos de Alonso de Covarrubias", Archivo Español de Arte, LVII, 225, 1984, pp. 96-108.
${ }^{68}$ F. LAYNA SERRANO, "Alonso de Covarrubias y la iglesia de la Piedad en Guadalajara", Boletín de la Sociedad Española de Excursiones, LXV, 1941, pp. 40-48. 